artelogie

\section{Artelogie}

Recherche sur les arts, le patrimoine et la littérature de l'Amérique latine

$10 \mid 2017$

Après le paysage : l'art, l'inscription et la représentation de la nature en Amérique latine aujourd'hui

\title{
Representación del paisaje americano desde la perspectiva artística de la sustentabilidad
}

\section{Araceli Barbosa Sánchez}

\section{(2) OpenEdition \\ Journals}

Edición electrónica

URL: http://journals.openedition.org/artelogie/811

DOI: $10.4000 /$ artelogie. 811

ISSN: 2115-6395

\section{Editor}

Association ESCAL

\section{Referencia electrónica}

Araceli Barbosa Sánchez, « Representación del paisaje americano desde la perspectiva artística de la sustentabilidad », Artelogie [En línea], 10 | 2017, Publicado el 05 abril 2017, consultado el 19 abril 2019. URL : http://journals.openedition.org/artelogie/811; DOI : 10.4000/artelogie.811

Este documento fue generado automáticamente el 19 abril 2019.

Association ESCAL 


\title{
Representación del paisaje americano desde la perspectiva artística de la sustentabilidad
}

\author{
Araceli Barbosa Sánchez
}

\section{Construcción cultural del paisaje}

1 El paisaje constituye un constructo cultural de la humanidad que adquiere connotaciones multidimensionales, tanto por su condición subjetiva como física. Alude a la forma en que se interactúa con el medio biofísico ${ }^{1}$ como biosocial. ${ }^{2}$ De tal manera, que se le concibe en su acepción geográfica, territorial, simbólica, estética, por citar algunas.

2 Ramon Buxó (2006:1), ha subrayado el carácter histórico que adoptan los paisajes dentro del variado mosaico que conforman actualmente. Afirma que su índole depende de su historia, de la humanización del territorio y de la geografía, concomitante a su evolución ecológica:

3 Los paisajes son esencialmente construcciones multidimensionales, resultado de la interacción de estructuras históricamente determinadas y de procesos contingentes. Como marco de la actividad humana y escenario de su vida social, el paisaje agrario, y los paisajes humanos en general, son una construcción histórica resultante de la interacción entre los factores bióticos y abióticos del medio natural. Cualquier interpretación histórica debe partir de la comprensión de esta dinámica. Es necesario, por tanto, que consideremos los paisajes como consecuencia de la coevolución socionatural a largo plazo. Por otra parte, desde el punto de vista evolutivo, los paisajes son resultado de la 'dependencia histórica de sentido', es decir, que con frecuencia, emergen elementos arbitrarios, no previstos, que determinan el posterior desarrollo histórico.

4 En el ámbito artístico, el paisaje responde a la representación subjetiva de la mirada, de la relación que se establece entre la psique humana y su alteridad constitutiva: la naturaleza. Javier Maderuelo (apud., Delgado, 2013:59) argumenta que: 
[...] el paisaje no es un ente objetual ni un conjunto de elementos físicos cuantificables, tal como lo interpretan las ciencias positivas, sino que se trata de una relación subjetiva entre el hombre y el medio en el que vive, relación que se establece a través de la mirada.

De ahí que la estetización del paisaje refiera a una construcción multidimensional, en la que la psique, la mirada, la simbolización y la interacción con el medio, entre otros factores, connoten su significación artística.

En la actualidad, la estética del paisaje americano remite a temáticas ambientales como resultado del paradigma cultural ecológico que desde mediados del siglo XX, ha evidenciado la irracional relación de los seres humanos con su entorno. La explotación de los recursos naturales con las consecuentes problemáticas ambientales, como: el calentamiento de la atmósfera terrestre y de los océanos, el cambio climático, la degradación de los ecosistemas, la contaminación del aire, agua y tierra, la extinción de especies animales y vegetales. Disturbios ambientales que han generado la pérdida de la biodiversidad, el mal uso de los recursos naturales renovables y no renovables por citar algunos, y que afectan la vida de la población global. Estos desastres ecológicos han suscitado el interés de los/as artistas por promover la sustentabilidad ${ }^{3}$ planetaria a través del arte.

\section{Enfoque transdisciplinario arte/medio}

7 Abordar la relación arte/medio, involucra la reflexión crítica acerca de la forma en que se construye el conocimiento ambiental. Significa replantearse de qué manera la especialización disciplinaria ha circunscrito el estudio del medio únicamente en función del campo ecológico, provocando su disociación de los demás ámbitos del conocimiento.

Conforme a la firme convicción que el estudio de la dimensión ambiental debe ser transversalizado a todos los ámbitos del conocimiento. Se aduce el enfoque teórico transdisciplinario con el fin de promover conciencia crítica acerca de la preservación del medio, mediante la convergencia disciplinaria de las ciencias ambientales y las humanidades. Propuesta que involucra la generación del pensamiento relacional, integrador y multidimensional.

9 En esta perspectiva, la conjunción disciplinaria del arte y el ambiente, constituye un puente de acceso al ámbito de la naturaleza desde la perspectiva sensible de la creación artística del paisaje.

10 A través de esta afortunada fusión disciplinaria, la construcción del paisaje adquiere nuevos significados que sobrepasan su carácter estético para connotar aspectos culturales, antropológicos, ambientales, simbólicos, entre otros. Razón por la cual se justifica la pertinencia epistemológica arte/ambiente.

11 Es un hecho, como afirma Nicolescu Basarab (1996), que la necesidad indispensable de establecer nexos entre las diferentes disciplinas ha originado que desde el siglo $\mathrm{XX}$, se transite de la pluridisciplinariedad y la interdisciplinariedad, al surgimiento de la transdisciplinariedad:

12 La transdisciplinariedad, no siendo nada más una nueva disciplina o una nueva hiperdisciplina, se nutre de la investigación disciplinaria, la cual a su vez, se esclarece de una manera nueva y fecunda por el conocimiento transdisciplinario (BASARAB, 1996: 36). 
13 Esto significa que el pensamiento transdisciplinario no renuncia ni rechaza las disciplinas, sino que las integra con la finalidad de construir nuevos referentes epistemológicos para la mejor comprensión del mundo presente, en el cual uno de los imperativos es la unidad del conocimiento.

14 En nuestra época, la gran proliferación de saberes pone de manifiesto la necesidad de adaptación de nuevas mentalidades que se correspondan con éstos. (BASARAB, 1996: 32-35).

15 Es así que la racionalidad transdisciplinaria involucra la subversión del pensamiento unidisciplinario. De la visión excluyente derivada de la especialización disciplinaria que ha dado como resultado la simplificación del conocimiento. Esto sucede cuando en el afán por desentrañar las consecuencias últimas de un fenómeno se disocian o eliminan sus elementos complejos.

En este sentido, el filósofo francés Edgar Morin aduce que todo fenómeno de la realidad es complejo, por lo que no se puede prescindir de sus elementos constituyentes. Noción que resulta esencial para comprender nuestro mundo fenoménico.

Conforme a la perspectiva teórica del pensamiento complejo, ${ }^{4}$ concepto acuñado por el filósofo. Para poder acceder a la interpretación de nuestra realidad, debemos confiar en nuestra capacidad de discernir de acuerdo a lógicas alternativas a la racionalidad simplificante, concomitantes a la conjunción de diversas áreas del conocimiento.

En la medida que se promueva la generación del pensamiento complejo, se obrará un viraje epistemológico que revolucionará el conocimiento ambiental. Se trascenderá la visión simplificante que mediante la fragmentación de saberes, ha disociado las diversas esferas de la vida. Tal ha sido la crítica de Morin (2005:89):

El hombre es un ser evidentemente biológico. Es, al mismo tiempo, un ser evidentemente cultural, meta-biológico y que vive en un universo de lenguaje, de ideas y de conciencia. Pero, a esas dos realidades, la realidad biológica y la realidad cultural el paradigma de la simplificación nos obliga ya sea a desunirlas, ya sea a reducir la más compleja a la menos compleja. Vamos entonces a estudiar al hombre biológico en el departamento de Biología, como un ser anatómico, fisiológico, etc., y vamos a estudiar al hombre cultural en los departamentos de ciencias humanas y sociales. Vamos a estudiar el cerebro como órgano biológico y vamos a estudiar al espíritu, the mind, como función o realidad psicológica. Olvidamos que uno no existe sin el otro; más aún, que uno es, al mismo tiempo, el otro, si bien son tratados con términos y conceptos diferentes.

Ciertamente la visión simplificante que resulta del pensamiento anclado en fronteras disciplinarias, ha trastocado la noción compleja de la dimensión humana, circunscribiéndola a lógicas reduccionistas.

21 Por tanto, transcender este tipo de racionalidad que constriñe y coarta el conocimiento imposibilitando su complejización, precisa de un nuevo andamiaje teórico sustentado en la construcción revolucionaria del pensamiento complejo y transdisciplinario.

\section{Convergencia de las ciencias ambientales y el arte}

Desde el enfoque transdisciplinario la conjunción de las ciencias ambientales y las humanidades, lejos de constituir ámbitos separados y excluyentes, adquieren pertinencia 
gnoseológica. Postura que ha promovido la filósofa María Novo (2002: s/p), directora de la Cátedra Unesco de Educación Ambiental, así como del proyecto ECOARTE. lentamente y a contracorriente se viene gestando, asumiendo el carácter transdisciplinario del conocimiento. Tal es el caso de la vinculación entre arte y ecología. 
Los antecedentes de la relación entre arte y medio se remontan a inicios de la década de los sesenta y comienzos de los años setenta, cuando se manifestó el interés por la ecología. Como disciplina científica, ésta se creó a finales del siglo XIX con el biólogo alemán Ernst H. Haeckel. En 1935, Tansley aportó la noción central de «ecosistema», para definir el objeto de estudio de esta ciencia.

Los aportes científicos del campo ecológico evidenciaron la urgente tarea de realizar un cambio de paradigma cultural que contemplara el desarrollo humano en equilibrio con la naturaleza y en función de la implementación de sistemas de producción sustentables.

Fue el año de 1969, en California, cuando se conjugó la unión entre la ecología científica y la toma de conciencia de las degradaciones del medio natural, no sólo locales, sino en lo sucesivo globales: "que afectan a la alimentación, los recursos, la salud y el psiquismo de los seres humanos. Se obró así el paso de la ciencia ecológica a la conciencia ecológica" (Morin, apud., Roque, 2011: 268).

El surgimiento de la conciencia ecológica legitimó el discurso ambiental y la necesidad de imponer límites al progreso económico; a la explotación irracional de los recursos naturales. Lo que propiciaba su devastación, de tal forma que el desarrollo en el sistema de producción capitalista tendría que tornarse sustentable.

La toma de conciencia acerca de la importancia de promover la sustentabilidad planetaria legitimó el discurso ambiental, ya que hasta antes de este hecho, las preocupaciones ecológicas habían sido consideradas opuestas al ideal de progreso. Además se produjo la unión entre la conciencia ecológica y una versión moderna del sentimiento romántico de la naturaleza que se había desarrollado, principalmente entre la juventud en el transcurso de la década de 1960. Dicho sentimiento halló en el mensaje ecológico una justificación racional. Hasta entonces, todo retorno a la naturaleza se había percibido en la historia occidental moderna como irracional, utópico y en contradicción con la evolución del «progreso» (Morin, apud., Roque, 2011: 268).

El espíritu ecologista se extendió a otros campos del conocimiento, fomentando el interés por el medio. En el ámbito artístico suscitó el redescubrimiento de la naturaleza, no como objeto de representación, sino como protagonista activa de un arte que interactuaba con ella.

El binomio arte/ambiente se generó en el contexto del movimiento ecologista de los años sesenta cuando los artistas, en su mayoría anglosajones, comenzaron a concebir la naturaleza como soporte de sus obras a partir de su intervención en espacios abiertos. En consecuencia, la estetización del paisaje se produjo en ambientes naturales. Surgía el "Land Art" abreviación del término en inglés landscape que significa "paisaje". En su traducción al castellano se le ha denominado como arte del paisaje. La crítica ha empleado diversos términos para referirlo, ya sea como arte ecológico, arte medioambiental, arte de la tierra, entre otros (Delgado, 2013:58).

Conforme a su devenir histórico, las expresiones artísticas del arte ambiental se han transformado. Si bien en el inicio, la producción estética mayoritariamente se centró en la naturaleza como soporte de las obras. En la actualidad, el arte ambiental asume una postura política que busca promover un cambio de paradigma cultural para salvaguardar la vida en el planeta. Por lo que en este texto, se propone que la denominación más adecuada para referirlo, es la de: arte para la sustentabilidad.

39 Esta conceptualización manifiesta su sustento teórico transdisciplinario. Se adecua con mayor precisión a la visión compleja del medio. En tanto que está indisolublemente unida 
a las dimensiones afectivas, espirituales, éticas, intelectuales, estéticas, biológicas, sociales, económicas, entre otras, de la condición humana en relación al ambiente. Manifiesta el sentido plural de las miradas que construyen paisajes artísticos multidimensionales. Reflejo de la relación que mantienen los seres humanos con su entorno natural.

\section{Discursos visuales para la sustentabilidad} biológicos, físico-químicos, informáticos, económicos, políticos y sociales, a través de una multiplicidad de temáticas, por lo que la colaboración transdisciplinaria emerge como resultado natural de este proceso. conocimiento. El interés de las/os artistas por los procesos ambientales ha dado como resultado la colaboración fecunda entre científicos de áreas, como la física, la química, la biología, la genética, la informática, la antropología, la pedagogía, la sociología, etcétera. Es una forma de trabajo conjunto que posibilita la producción artística a través de la interacción de la ciencia, la tecnología y el arte.

En esta perspectiva, la conjunción arte y sustentabilidad, promueve la unión disciplinaria de las ciencias ambientales y las humanidades para gestar conciencia crítica acerca de las acciones antropogénicas ${ }^{5}$ y sus efectos sobre el medio.

El arte posee un gran potencial para coadyuvar a la transversalización de la sustentabilidad, constituyéndose en vía de conocimiento de la dimensión biofísica, espiritual, ética, estética, social, económica, de los seres humanos, en estrecha armonía con la naturaleza.

La producción de paisajes artísticos desde la mirada de la sustentabilidad fomenta la ética para la vida, la convivencia ecosistémica, ${ }^{6}$ la conexión con nuestra naturaleza biótica ${ }^{7}$ y abiótica. ${ }^{8}$ Apela al sentimiento de reconocimiento de nuestra interdependencia con la naturaleza, a fin de asumir nuestra pertenencia a ella y no a la inversa.

El propósito de los/as artistas que producen arte para la sustentabilidad consiste en acercarnos a la estética de la naturaleza. De ahí, que se planteen la realización de narrativas visuales que expresen el respeto hacia todas las formas de vida en el planeta. Desean propiciar en nosotros sentimientos de empatía con la naturaleza. Sensibilizarnos acerca de la complejidad de sus procesos biológicos, de sus fuerzas telúricas. En suma, buscan hacer emerger en nosotros el sentimiento de biofilia, esto es, amor a la vida.

Los/as creadores/as con conciencia ambiental confían en el poder del arte para visibilizar los estragos ambientales causados por los depredadores sistemas de producción en el capitalismo globalizado. De la correlación que existe entre la explotación de los recursos naturales y los irracionales estilos de vida de la sociedad de consumo. De este modo, los/ as productores/as artísticos/as se dan a la tarea de producir narrativas visuales que involucran analogías entre los trastornos ecológicos, sociales y políticos entre otros.

Se impone precisar que el arte para la sustentabilidad se fundamenta en el respeto absoluto hacia la vida como fundamento ético y estético. Ergo, las obras deben de guardar coherencia en su estructura conceptual, concomitante a su estructura material. Estrictamente, una obra de arte para la sustentabilidad debe contemplar recursos 
discursivos que semánticamente connoten el respeto a la integridad del medio, tanto en su estructura interna como externa:

Una obra de arte ecológico guarda en su estructura externa (técnica), armonía con el ambiente y en su estructura interna es armónica con los fines que persigue la ecología como ciencia, consecuentemente posee valor ético y no sólo estético (Guerrero, 1998:21).

En la actualidad, los/as artistas con conciencia ambiental que realizan discursos artísticos para la sustentabilidad, tienen claro que su propuesta no se limita únicamente a un objetivo estético o expresivo, sino que involucra un fin ético.

De hecho, se han planteado salvaguardar la integridad ambiental, reparando daños generados por las actividades humanas sobre el medio con el objetivo de sensibilizar y motivar a la población acerca de la importancia y cuidado del hábitat natural:

51 Es en este contexto donde se afirma el arte ecológico contemporáneo como un nuevo género de arte público que explora nuevos estilos de vida con base en el cambio social, ecológico y educativo. Los artistas hacen el trabajo cultural mediante el arte en relación con las características sistémicas de lo humano, lo vegetal y lo animal interactuando en localizaciones geográficas específicas (Pérez, 2016:1).

Al respecto, Novo está convencida (2002: s/p) que el arte y la ciencia en el siglo XXI tienen el reto de plantear nuevas visiones y propuestas:

53 En este desafío, las posibilidades del arte y de los artistas se amplían notablemente cuando, acercándose a la Naturaleza y a los ambientes creados por el ser humano, los abordan de la mano de la ciencia y no de espaldas a ella, para la recuperación de lo que, por largo tiempo, parecía perdido:

- la unidad del conocimiento, como expresión de la unidad de lo real.

- el sujeto (en la ciencia, en el arte) como sujeto que piensa, siente, imagina...

54 A esta fusión de arte y ciencia, Novo (2002: s/p) la ha denominado ECOARTE: "un movimiento en el que la obra de arte se sitúa en la interfase entre lo que la ciencia nos dice y lo que la imaginación nos advierte, también entre el sujeto histórico y su contexto, el medio ambiente".

Apreciación que confirma que en el siglo XXI, la interacción fecunda entre la ciencia y el arte conlleva la generación del conocimiento ambiental. Fundamental para promover el paradigma de la sustentabilidad.

Por su parte, la artista, crítica e historiadora del arte Suzi Gablik (apud., Cruet, 2011:9-10), manifiesta su esperanza por un arte nacido de un nuevo paradigma cultural que promueva en la sociedad global el interés por la ecología. Opina que: "Los artistas deben hacer arte responsable con la Tierra y la humanidad".

En este contexto el arte del paisaje contemporáneo se presenta como promotor de la estética de la sustentabilidad mediante representaciones y simbolizaciones de la naturaleza inéditas. En suma, es un arte al servicio de la vida.

El contexto mexicano: Arte para la sustentabilidad

México, la preocupación ambiental por parte de los/as artistas que impulsan la relación arte/medio/sociedad, se centra en propiciar conciencia colectiva de lo que significa la sustentabilidad desde la perspectiva del arte público. Así se aprecia en la realización de obras mediante la intervención ${ }^{9}$ artística, ya sea en espacios urbanos o áreas naturales. Estrategia que resulta idónea dada la función social del arte público para establecer comunicación con diversos sectores de la sociedad. 
60 Entre los/as artistas que desde mediados del siglo XX y principios del siglo XXI han realizado discursos artísticos para la sustentabilidad, se encuentran, Marcos Kurtycz, Mauricio Guerrero, Helen Escobedo, Arcángel Constantini, Betsabée Romero, César Martínez, Diego Toledo, Iván Edeza, Anette kuhn, Miguel Calderón, Minerva Cuevas y Thomas Glassford por ejemplo.

61 Fiel a su espíritu transdisciplinario, el arte para la sustentabilidad se vincula a la didáctica ambiental a través del arte público. El artista Mauricio Guerrero, ${ }^{10}$ considera que la interacción con los espectadores resulta vital para la realización de obras ambientales. Convencido de la fusión entre arte y educación para la sustentabilidad ${ }^{11}$ opina que existen diversas maneras de conocer el medio para aprender a cuidarlo desde distintos campos disciplinarios:

El arte, no ya en su concepción más convencional, sino concebido como un vehículo y no un fin en sí mismo puede sintetizar contenidos o mostrando accesiblemente facetas ocultas de la problemática ambiental, no con una obra esporádicamente desde luego, sino con muchas y en todas partes, en todos los campos, y a todos niveles (1998:51).

Un ejemplo conspicuo de la forma en que opera el arte para la sustentabilidad, con una función social, política y didáctica, es el trabajo artístico de Guerrero. En este sentido, se refiere una de sus obras que resulta paradigmática por su significación conceptual y discursiva que promueve la alfabetización ambiental, (AA) ${ }^{12}$ con un marcado sentido ético, estético y socioambiental.

\section{Las aves migratorias en la Nube Serpiente}

La obra de Mauricio Guerreo, denominada Las Aves migratorias en la Nube Serpiente (1996), realizada en el Lago Recreativo de Texcoco, localizado al suroeste de valle de México, plantea la relación arte/ambiente/sociedad. Representa un elocuente testimonio del accionar del arte público y social al servicio de la sustentabilidad. En palabras de Guerrero, esta propuesta visual involucra:

[...] el arte como un puente, como un medio con una o varias funciones: de comunicación, de sensibilización, de reflexión crítica, pero no más de adormecimiento y complacencia.

Este planteamiento cuando considera los problemas ambientales trae de nueva cuenta a la discusión la dicotomía entre cultura y naturaleza, sobre todo en lo que atañe al medio urbano, donde estos problemas suelen ser agudos (GUERRERO, 1998:15).

Habría que comenzar por referir que la planeación de esta obra, se ha sustentado en una detallada investigación acerca de las condiciones del espacio, así como de los recursos, tanto materiales como conceptuales para dar sentido a la construcción del discurso visual. Con este propósito, Guerrero se abocó a la consulta de fuentes históricas, la realización de entrevistas con informantes clave, indagación de las condiciones geográficas y atmosféricas del lugar, etcétera, para desarrollar su proyecto artístico in situ. El artista comenta:

[...] estaba claro: evitar una obra superficial apoyada en una idea de mexicanidad mal entendida por imágenes sin arraigo alguno, tampoco una obra abstracta producto más del voluntarismo y amparada en la libertad de creación del arte, donde cualquier cosa (objeto o no) funcionaría, que se convirtiera, entonces en otro problema y no en la propuesta alternativa para pensar nuevamente al arte en interacción con el ambiente y el público (GUERRERO, 1998:154). 

arriban del norte de Estados Unidos y Canadá, a los cuerpos de agua de lo que antiguamente constituía el Lago de Texcoco. La restauración ecológica de este sitio, ha permitido que las aves regresen a la región. un fenómeno natural. No es un espectáculo para hacer llorar o reír en forma alienada semejante a los que nos tiene acostumbrados la industria del entretenimiento, particularmente la televisión privada, es una ceremonia de alimentación que invita a pensar, por lo menos un momento, en nuestros orígenes y a recordar que somos parte de la naturaleza.

Es una propuesta que asocia el pensamiento ancestral mexicano con nuestras necesidades actuales (Guerrero, 1998:98).

71 En la modalidad de performance/instalación, la acción inició al amanecer del 30 de noviembre de 1996. Guerrero eligió este mes, basado en el antiguo calendario de la cultura náhuatl que marca los meses de noviembre y diciembre, como la época en que se realiza la migración de las aves.

De acuerdo con el sistema calendárico mexica ${ }^{13}$ se denomina "Quecholli", a la décimo cuarta veintena de días que en náhuatl significa "pájaro de pluma roja", cuya deidad o numen regente es Mixcoatl, representado como un guerrero, un arquero, -figura que comúnmente se identifica con la constelación de Sagitario-, al que se le asocia con la Vía Láctea o "nube serpiente". Esta asociación simbólica permite inferir que, el "mes de las aves", connota la abundancia de estrellas de la Vía Láctea. Por lo tanto, en la cosmovisión náhuatl: "La serpiente de nubes" (Mixcoatl) representaba la abundancia de caza que provenía del cielo" (GUERRERO, 1998:73).

Con el fin de experimentar este sorprendente acontecimiento de la naturaleza, se convocó a todo el público a formar parte de un evento artístico-didáctico que conjugaba ecología e historia; a participar en una celebración colectiva como un acto comunitario, ritual, festivo y de agradecimiento a la "serpiente de nubes" por los dones conferidos.

anvitación se hizo extensiva a diversas instancias de la sociedad: artistas visuales, instituciones abocadas a la difusión de la cultura, organismos públicos y privados preocupados por el ambiente, proveedores de insumos diversos, así como a estudiantes de niveles medio y superior.

Como parte del proyecto, se realizaron talleres de sensibilización ambiental a través del arte, dirigidos a profesores, instructores y alumnos, de escuelas secundarias públicas. ${ }^{14} \mathrm{De}$ este modo, se concibió la realización de "vasijas-ave", a partir de modelos suministrados y la utilización de envases de leche reciclados de material de "tetra pak", cortado, doblado 
y pegado. El objetivo consistió en confeccionar recipientes para ofrendar alimento a las aves que arribaran al lago. Actividades encaminadas a:

Estimular una actitud diferente ante el entorno y motivar conciencia ambiental a partir de formar parte de un fenómeno natural particular, por medio de una actividad específica con una aplicación concreta donde se manifiesta la creatividad de estos grupos humanos ( GUERRERO, 1998:109).

Los talleres fueron impartidos por colaboradores, como docentes y alumnos de las licenciaturas de Artes Plásticas, Diseño, Fotografía y Video, que participaron sin cobrar remuneración y sin otro interés que abogar por la conservación de medio.

Del mismo modo, se abrieron dos foros para exponer la temática artístico- ambiental del proyecto a estudiantes de secundaria y preparatoria. Uno de éstos se realizó en El Museo de Ciencias de la UNAM. Mientras que el otro se efectuó en el Museo Universum (consultar anexo).

Con el propósito de ofrendar alimento a las aves, se solicitó a los participantes que, el día del evento, llevaran grano. Toda vez que constituía una forma de propiciar una acción colectiva y motivar el espíritu de agradecimiento; más que el simple hecho de alimentarlas. "Acudir con un "tesoro", es decir, el grano de la ofrenda que traerían desde sus lugares de origen hasta la ribera de lago" (GUERRERO, 1998:115). El acopio de grano también se efectuó a través de donaciones de empresas.

Otro aspecto de la obra se refiere a la intervención artística del lago con ocho esculturas de madera, en forma de estrella, que conformaban la constelación del arquero. Sobre el particular comenta Guerrero (1998:112): "El Lago Recreativo se convirtió en nuestra galaxia o Mixcoatl, "Nube serpiente" y en su interior flotaron ocho "balsas-estrella" que representaban a la constelación del arquero". Sobre estas estructuras se colocó el alimento para las aves.

81 Asimismo, se realizó otra instalación a la entrada del lago que consistió en la colocación de doscientas "vasijas-ave", sobre una superficie aproximada de 50 metros de largo por 2.5 de alto, indicando entre otras cosas el suceso del día.

82 El performance realizado por Guerrero se efectuó en la ribera del lago. La acción inició cuando el artista ataviado con pantalón y camisa negros, descalzo y portando los atributos de Mixcoatl, esto es, arco, flecha y máscara blanca con pico de ave, se dispuso a trazar sobre el terreno la figura de "Nube serpiente", esparciendo cal para este fin. $\mathrm{Al}$ tiempo que, enunciaba el mito cosmogónico con estas palabras: “(...) ésta gran banda celeste es la Nube serpiente...". Enseguida tomó un cilindro de aproximadamente $30 \mathrm{~cm}$ de diámetro, y metro y medio de altura que contenía en su interior hielo seco, para dibujar en el aire -mediante humo blanco-, la figura que simbólicamente representaba a la Vía Láctea. Una vez hecho esto, utilizó un arco y una flecha, para señalar en el cielo los cuatro rumbos del universo. Finalmente lanzó la flecha hacia el rumbo del sur (GUERRERO , 1998:111).

Por su parte, cada uno de los asistentes al evento depositó su ofrenda de grano en las "balsas estrella". Su participación fue parte de la acción, en tanto que se concibió:

[...] como una obra de factura colectiva donde se rompe la actitud contemplativa del hombre ante la naturaleza, por una acción ética y estética. En ese instante se puso en movimiento el lago y se cargó de energía; se agradeció a la naturaleza y se le pidió que continuase ocurriendo el fenómeno (GUERRERO, 1998:112-115). 
84 devienen imágenes representacionales de la forma en que se concibe e interactúa con la realidad. Desde los tiempos más remotos de la antigüedad los paisajes entrañan el misterio de la naturaleza. El arte primevo da testimonio de ello a través del shamanismo y del principio de magia imitativa, hasta el arte contemporáneo transdisciplinario convergente con las ciencias más avanzadas.

El arte latinoamericano tiene la oportunidad hic et nunc de coadyuvar en la empresa más ingente de la humanidad. La de preservar la vida en el planeta, guiado por la racionalidad sustentable para propiciar la coexistencia armónica con los procesos vitales de la naturaleza. Esta postura posibilitará la gestación de nuevos paradigmas estéticos que generen inéditos paisajes e interpretaciones del mundo, de nosotros mismos, así como, de las identidades de los pueblos americanos. La imaginación creadora de la humanidad debe conducirnos hacia la construcción de paisajes multidimensionales que connoten la sustentabilidad planetaria. 


\section{BIBLIOGRAFÍA}

barbosa Alma, La intervención artística de la ciudad de México, México, Conaculta-Inba, ICM, 2003.

barboSA Araceli, Educación y Arte para la Sustentabilidad, México, Juan Pablos Editor, UAEM, 2015.

gUERRERo Mauricio, El fenómeno de las aves migratorias en la ciudad de México. Una obra de arte urbano no-objetual, tesis de Maestría, Universidad Nacional, Autónoma de México, México, D.F, 1998.

moRIN Edgar, Introducción al pensamiento complejo, edición española a cargo de Marcelo Pakman, Barcelona, España, Editorial Gedisa, S.A., $8^{\circ}$ reimpresión, 2005.

\section{Webgrafía}

BASARAB Nicolescu, La Transdisciplinariedad Manifiesto, México, Multiversidad Mundo Real Edgar Morin, A.C., Edición 7 saberes, Traducción: Mercedes Vallejo Gómez, 1996. Disponible en internet: http://es.scribd.com/doc/57161979/Manifiesto-de-la-Transdisciplinariedad\#scribd [Consultado agosto 2016].

BUXÓ I CAPDEVILA Ramon, “Paisajes culturales y reconstrucción histórica de la vegetación”, in Ecosistemas, vol. 15, núm. 1, enero-abril, Asociación Española de Ecología Terrestre Alicante, España, 2006, pp. 1-6, Disponible en internet: http://www.redalyc.org/pdf/540/54017105001.pdf [Consultado septiembre 2016].

CRUET Lionel, Arte ecológico: la presencia de la gestión, a través de las obras de: Joseph Beuys (1921-1986), Ana Mendieta (1948-1985) y Mark Dion (1961-), Tesina presentada como requisito para la obtención de Bachiller en la Escuela de Artes Plásticas, San Juan, Puerto Rico, Departamento de Imagen y Diseño, 2011. Disponible en internet: http://www.lionelcruet.com/ EAP_BFA_Thesis_Lionel_Cruet_2011.pdf [Consultado agosto 2014].

DELGADo Francisco Javier, Arte y naturaleza. El Land Art como recurso didáctico para la educación artística, Primer Premio, XXIV Edición Premios Joaquín Guichot, Antonio Domínguez Ortiz. Junta de Andalucía, Consejería de Educación, 2013. Disponible en internet: http:// agrega.juntadeandalucia.es/repositorio/14022013/42/es-an_2013021411_9145208/ADO24/ ado24_1p2/03.pdf [consultado septiembre 2016].

GONZÁLEZ GAUDIANo Edgar, Blog. ¿Desarrollo sustentable o sostenible?, 2012. Disponible en internet: http://edgargonzalezgaudiano.blogspot.mx/2012/12/desarrollo-sustentable-o-sostenible.html [Consultado mayo 2014].

Novo María, "La complementariedad ciencia-arte para la construcción de un discurso ambiental integrado", in Revista Latinoamericana, Universidad de los Lagos, 2012. Disponible en internet: http://dialnet.unirioja.es/servlet/articulo?codigo=2798860 [Consultado agosto 2016].

PÉREZ Eugenia, Arte de la Tierra otras Geografías, 2016. Disponible en internet: http:// m.exam-10.com/biolog/33456/index.html [Consultado septiembre 2016].

RoQUE Maria-Àngels, "Hacia el pensamiento ecologizado. Entrevista a Edgar Morin”, Quaderns de la Mediterrània, 16, 2011, pp.268-272. Disponible en internet: http://www.iemed.org/observatori/ arees-danalisi/arxius-adjunts/qm-16-es/roquema_hacia\%20el\%20pensamiento\%20ecologizado\% 20edgar\%20Marin_qm16.pdf [Consultado agosto 2016]. 


\section{ANEXOS}

Universum, es el Museo de las Ciencias de la Universidad Nacional Autónoma de México, (UNAM). Es un museo dedicado a promover la ciencia y la tecnología al público.

Inaugurado el año de 1992.

Portada del folleto de la obra: Las Aves migratorias en la Nube Serpiente

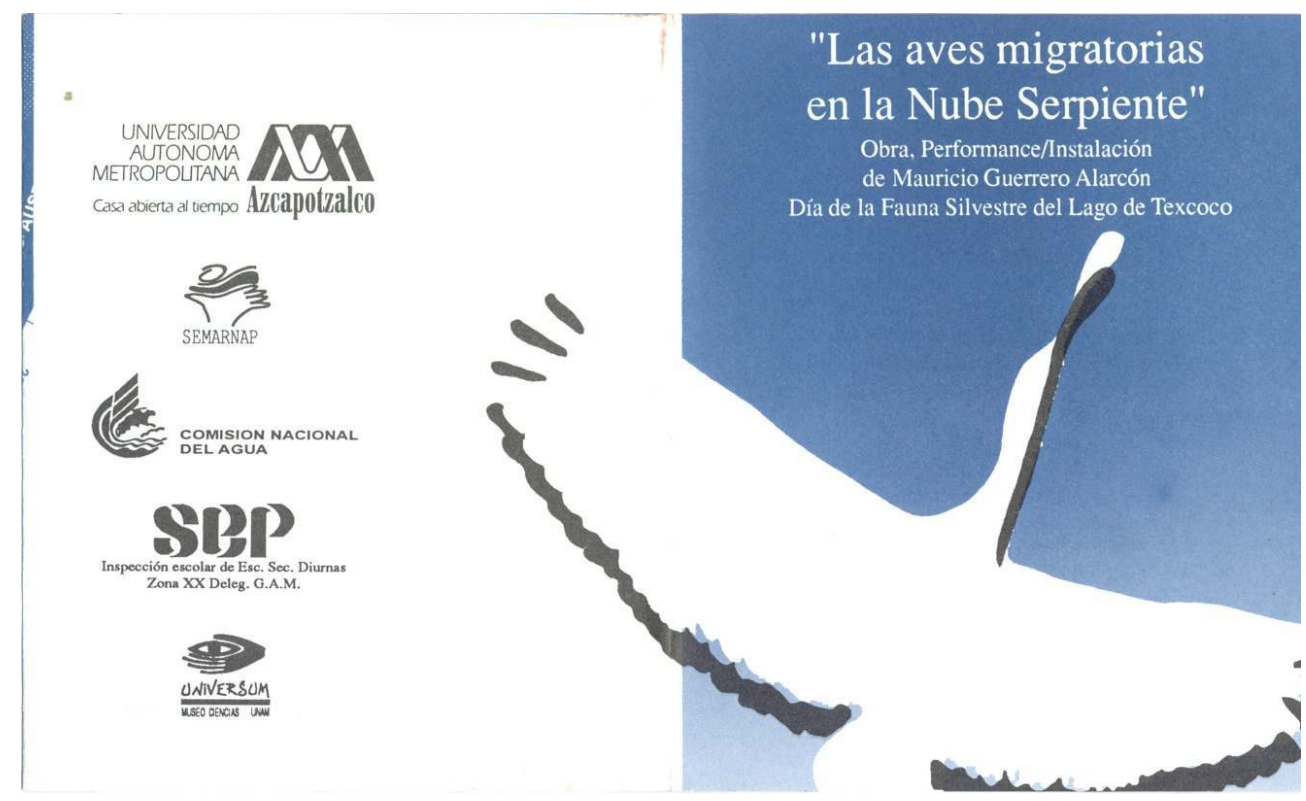

entregado durante el evento en el lago recreativo del Lago de Texcoco.

Fotos cortesía del artista Mauricio, Guerrero. 1996. 
La acción de Mixcoatl en la obra: Las Aves migratorias en la nube serpiente

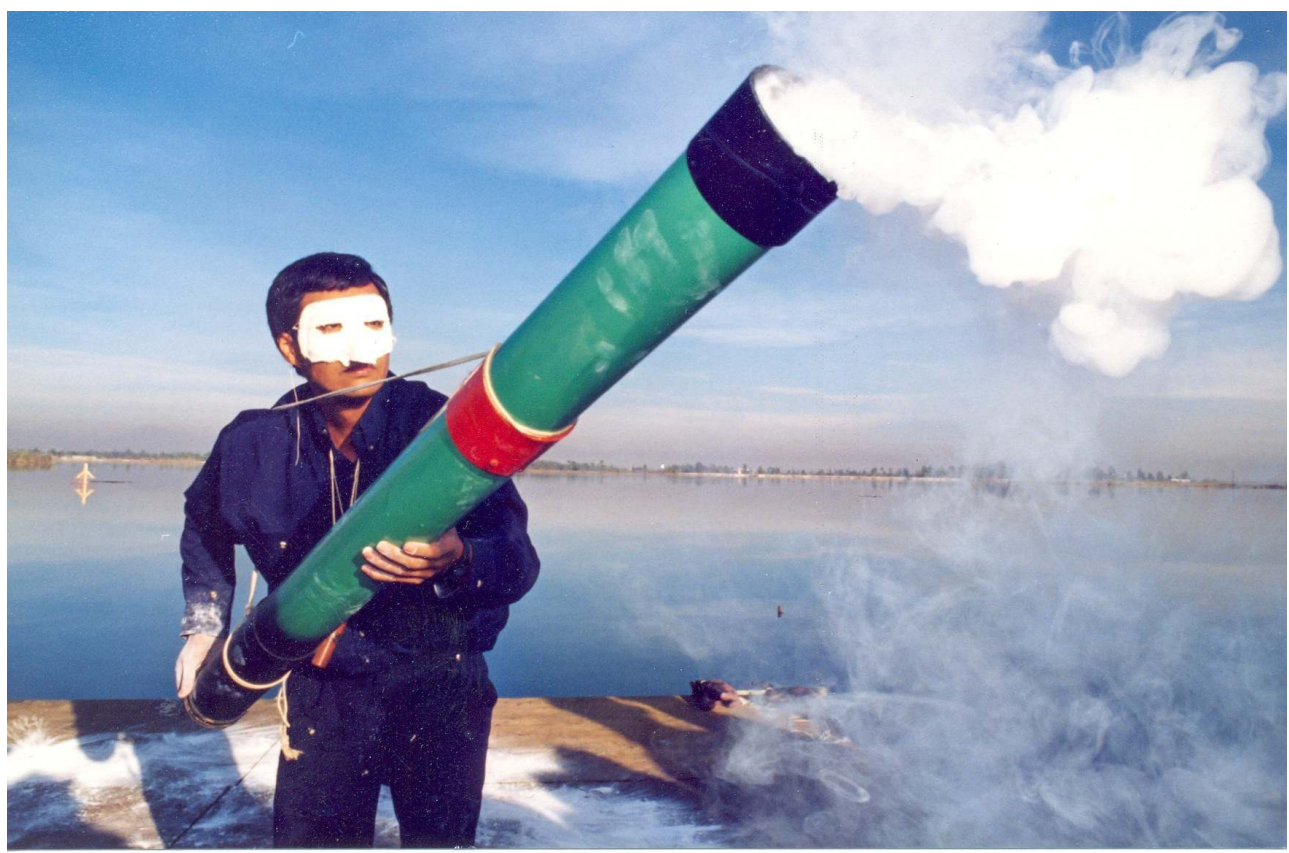

Fotos cortesía del artista Mauricio, Guerrero. 1996.

Acción del arquero en dirección a la constelación de Sagitario y al centro de nuestra galaxia

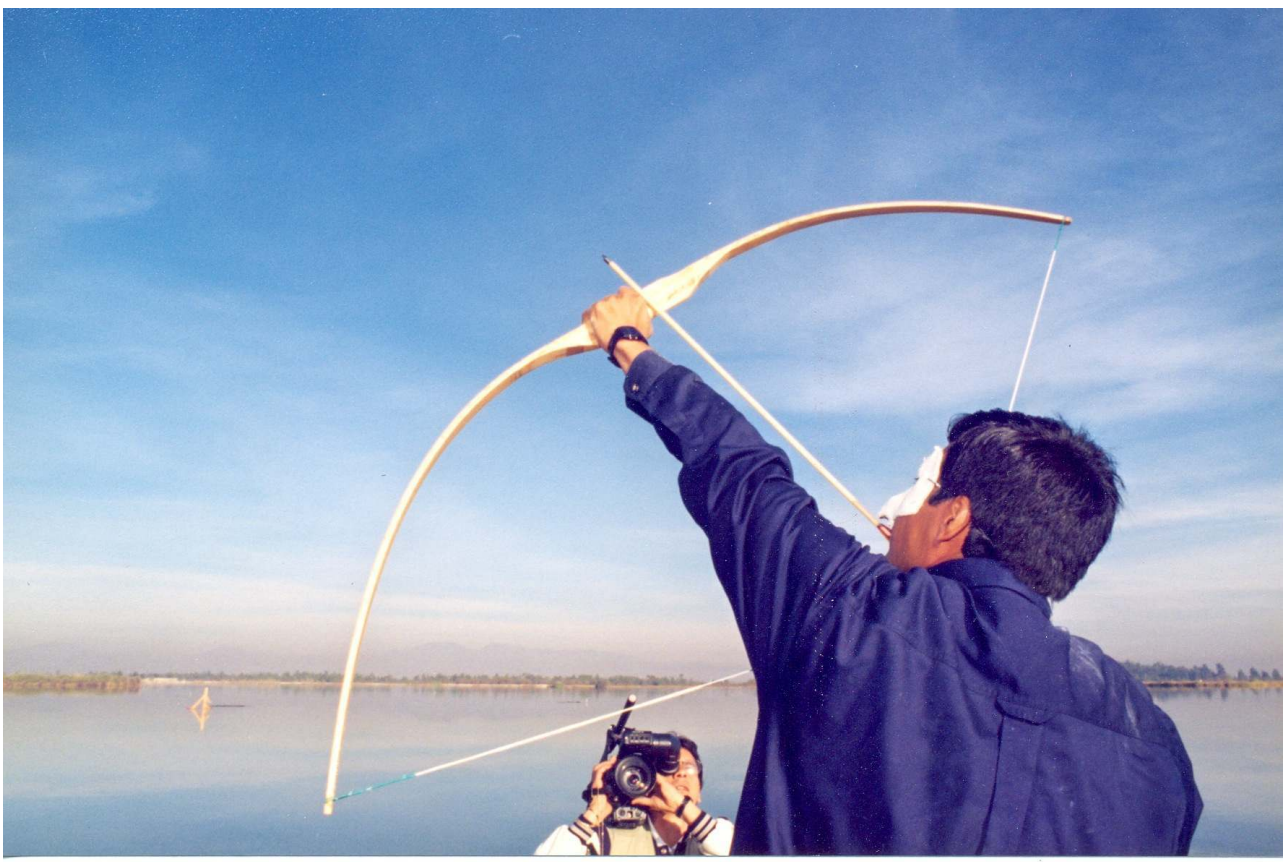

Fotos cortesía del artista Mauricio, Guerrero. 1996. 
Las "vasijas-ave" creadas por los escolares a partir de un tipo hecho de cartón "tetra pak"



Fotos cortesía del artista Mauricio, Guerrero. 1996.

Dos "balsas estrella" flotan en el lago de un conjunto de ocho que representan las posiciones de la constelación de Sagitario

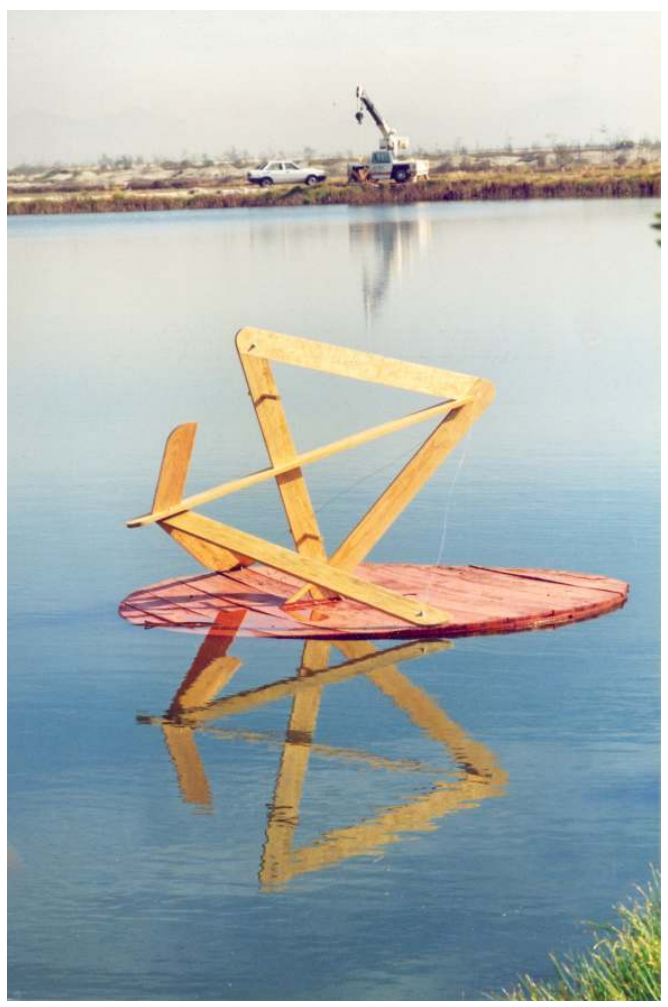

Fotos cortesía del artista Mauricio, Guerrero. 1996. 
"Balsa estrella", depósito que flota para los granos que se ofrecen en la acción del artista

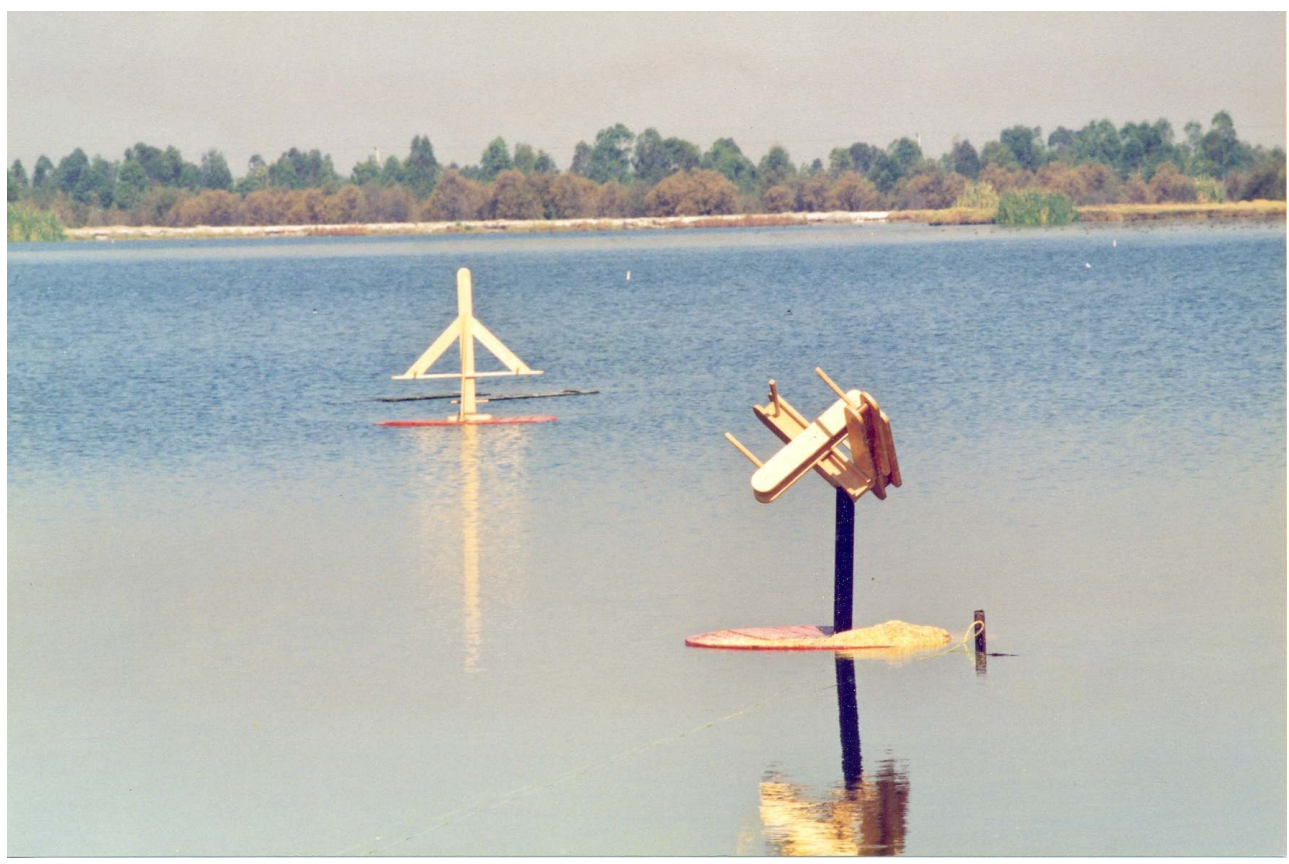

Fotos cortesía del artista Mauricio, Guerrero. 1996.

Panorámica del performance de Mauricio Guerrero, en el lago recreativo de Texcoco

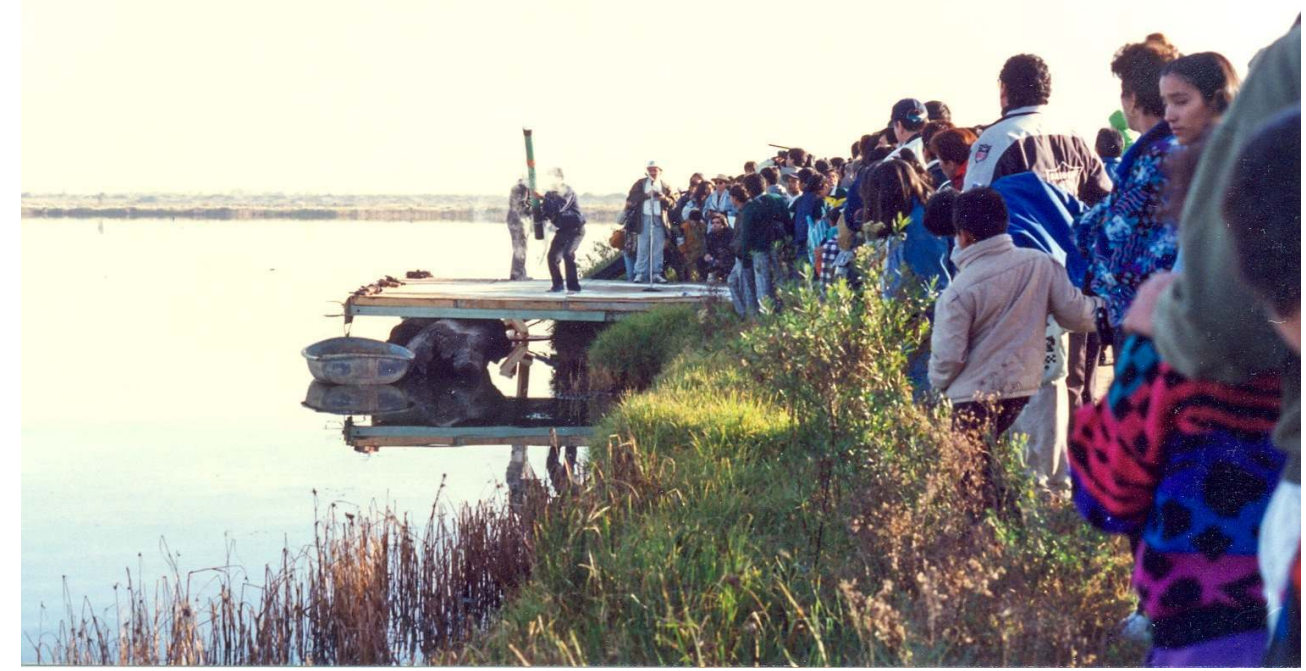

Público compuesto por escolares, profesores e invitados

Fotos cortesía del artista Mauricio, Guerrero. 1996. 


\section{NOTAS}

1. El medio biofísico engloba a los agentes que componen el medio ambiente natural como el clima, la flora y fauna, hidrogeología, geología, geomorfología, paisaje.

2. El medio biosocial refiere a los comportamientos sociales que en interacción con el ambiente, adoptan los animales incluido el ser humano.

3. El término de sustentabilidad remite sus antecedentes conceptuales a la propuesta emitida el año de 1987 por la Comisión Mundial sobre el Medio Ambiente y el Desarrollo (CMMAD). Las Naciones Unidas a través del "Informe Brundtland", expusieron el concepto de "desarrollo sostenible" para definir el proceso que contempla la satisfacción de las necesidades del presente sin comprometer las necesidades de las futuras generaciones. Es imperativo aclarar que la traducción de sustainable development, neologismo del idioma inglés a otros idiomas suscitó diversas interpretaciones, así por ejemplo, países como México, Argentina y Chile lo tradujeron como desarrollo sustentable, mientras que los otros países de América latina y España se inclinaron por sostenible. Brasil decidió utilizar sustentable en su traducción al portugués. Al final ambos conceptos se consideran sinónimos (GONZÁLEZ-GAUDIANO, 2012).

4. De acuerdo con Morin (2005), el pensamiento complejo está animado por una tensión permanente entre la aspiración a un saber no parcelado, no dividido, no reduccionista y el reconocimiento de lo inacabado e incompleto de todo conocimiento. Expresa lo complejo de todo razonamiento. Conforme a esta noción, se concibe la multidimensionalidad de los fenómenos, opuesta a la visión unidimensional, especializada, parcial que empobrece el mundo fenoménico. Por tanto, la complejidad plantea el imperativo de volver a religar lo que está desunido; lo que ha sido fragmentado en pos de alcanzar el conocimiento último de las cosas. Esto no significa que la complejidad pueda equipararse a la completud, ya que es inconmensurable, inabarcable.

5. Las acciones antropogénicas se refieren a los efectos, procesos o materiales que se derivan de las acciones humanas, como la agricultura y la ganadería, la urbanización, los asentamientos humanos, la explotación de los recursos naturales, la industria, por ejemplo.

6. La convivencia ecosistémica involucra la interrelación e interacción armónica que deben guardar los procesos sociales, económicos, culturales entre otros, con los procesos ambientales. Los efectos de unos, repercuten sobre los otros a nivel sistémico.

7. El término biótico alude a las condiciones características de los organismos vivientes o que mantienen un vínculo con ellos. También hace referencia a la biota, concepto que nombra a la flora y fauna de un territorio.

8. Abiótico, al contrario que biótico, refiere al entorno en que no se generan las condiciones necesarias para propiciar la vida. Nombra lo que no es propio de la naturaleza viviente.

9. La intervención artística remite al concepto de apropiación simbólica del espacio. Es una categoría de análisis que designa la incorporación sistemática de códigos artísticos al espacio público urbano o natural con múltiples significados, ya sean simbólicos, identitarios, políticos, territoriales, lúdicos, de género o ambientales, que por lo general asumen un carácter efímero. Mediante lenguajes y discursos artísticos opera la resignificación estética y cultural del espacio. En síntesis, la apropiación simbólica del espacio público urbano o natural connota su ocupación con fines ideológicos, estéticos, contraculturales, rituales, ambientales, etcétera (BARBOSA, 2003).

10. Artista visual, egresado de la Escuela Nacional de Artes Plásticas de la Universidad Nacional Autónoma de México, (UNAM). Posee grado de Maestría en Artes Visuales. Participó con grupos de búsqueda artística en proyectos utópicos de arquitectura prospectiva, grupo Tetraedro (1976-1977), IX Bienal de París; en el Salón Nuevas Tendencias 77 (1977-1978), Museo de Arte 
Moderno de Chapultepec, México, con el grupo março (1979-1983) en performances de participación colectiva en espacios alternativos o no tradicionales, Poema Urbano y Revista março.

11. La educación para la sustentabilidad (ES), se refiere a la educación específica acerca del medio, plantea la visión compleja de los fenómenos socioambientales, articulada al enfoque transdisciplinario de las ciencias ambientales. De esta forma, se posibilita la comprensión y el análisis crítico de cómo las actividades humanas están efectuando cambios de consecuencias adversas para la biosfera nunca vistas.

12. La alfabetización ambiental es un concepto que promueve la educación para la sustentabilidad, con el propósito de generar conciencia ciudadana acerca de la importancia de mantener una relación armoniosa y de respeto hacia el medio en el ámbito de la vida cotidiana y pública de la sociedad. Postura que aspira a fomentar valores ambientales tanto a nivel local como global.

13. Los mexica se regían por dos calendarios, uno religioso y otro civil, el religioso con base en un ritual cíclico ligado a concepciones agrarias, mientras que el civil concebía el tiempo de manera lineal y cotidiana. La celebración de los ritos consagrados a rendir culto a las diferentes deidades, se realizaba de acuerdo al calendario religioso, dividido en 13 periodos de 20 días cada uno, que hacían un total de 260 días. El calendario civil, constaba de 365 días, divididos en 18 veintenas de 20 días, al que agregaban 5 días considerados nefastos.

14. Escuelas secundarias públicas números $58,74,93,176,216,282$ y 285, zona norte del Distrito Federal en la Delegación Gustavo A. Madero, Inspección escolar XX, de la Secretaría de Educación Pública (SEP), contigua a la zona de lagos, y se llevó a cabo en los talleres de artes plásticas, en aulas de la materia de Educación Ambiental, durante un periodo de cuatro a cinco semanas (28 octubre de 1996 al 29 de noviembre del mismo año) (GUERRERO, 1998:109).

\section{RESÚMENES}

En el contexto artístico latinoamericano del siglo XXI, la representación del paisaje adopta la estética de la sustentabilidad. Connota la reflexión crítica de aquellos/as artistas con conciencia ambiental interesados/as en visibilizar las complejas acciones e interacciones que los seres humanos establecen con el medio y que determinan su conservación o degradación. A partir de la emergencia del paradigma ecológico del siglo XX, la relación arte/ambiente, se concibe como binomio convergente con la sustentabilidad. En el ámbito mexicano, la racionalidad sustentable se manifiesta en un discurso visual transdisciplinario que conjuga arte/medio/sociedad. Ejemplo de ello, es la obra Las aves migratorias en la Nube Serpiente de Mauricio Guerrero, que propone el arte como vía de conocimiento y conservación sustentable del medio.

Dans le contexte artistique latino-américain du XXIe siècle, la représentation du paysage adopte l'esthétique de la durabilité. Elle connote la réflexion critique de ces artistes qui sont dotés de conscience écologique, qui s'intéressent à la visibilité des actions et des interactions complexes qu'établissent les êtres humains avec l'environnement et qui en déterminent la conservation ou la dégradation. À partir de l'émergence du paradigme écologique du XXIe siècle, la relation art/ environnement, se conçoit comme un binôme convergent avec la durabilité. Dans le milieu mexicain, la rationalité durable se manifeste dans un discours visuel transdisciplinaire qui conjugue art/environnement/société. L'œuvre «Les oiseaux migrateurs dans le nuage serpent » 
de Mauricio Guerrero en est un exemple, qui propose l'art comme voie de connaissance et de protection durabilité de l'environnement.

\section{ÍNDICE}

Mots-clés: paysage, art, environnement, durabilité, art latino-américain

Palabras claves: paisaje, arte, ambiente, sustentabilidad, arte latinoamericano

\section{AUTOR}

\section{ARACELI BARBOSA SÁNCHEZ}

Dra. Historia del Arte por la Universidad Nacional Autónoma de México, profesora investigadora de la Universidad Autónoma del Estado de Morelos. Autora de los libros: Educación y Arte para la Sustentabilidad, Juan Pablos, UAEM, 2015, Arte Feminista en los ochenta en México. Una perspectiva de género, Juan Pablos, UAEM, 2009, Sexo y Conquista, UNAM, 1994. Líneas de investigación: Arte/Complejidad/Transdisciplina, Género y Arte, Arte y Sustentabilidad. araceli_barbosa[at]uaem.mx 